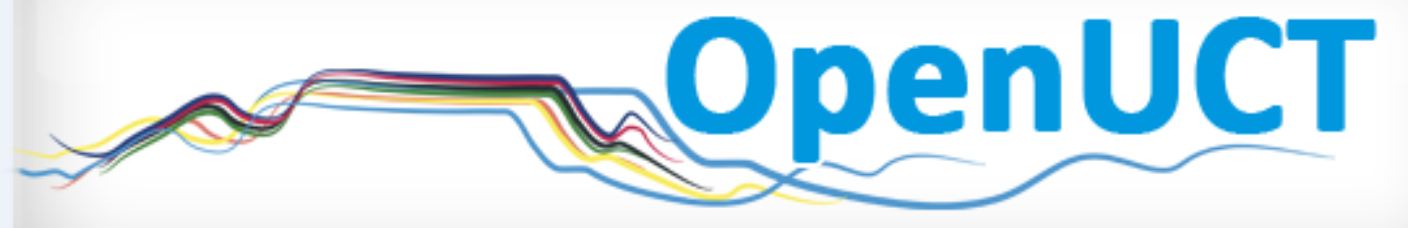

This is the post-print of Cooper, L. 2011. Activists within the academy: the role of prior experience in adult learners' acquisition of postgraduate literacies in a postapartheid South African university. Adult Education Quarterly. 61(1): 40-56.

It is made available according to the terms of agreement between the author and the journal, and in accordance with UCT's open access policy available: http://www.openuct.uct.ac.za/sites/default/files/UCTOpenAccessPolicy.pdf, for the purposes of research, teaching and private study. 


\title{
Activists within the academy: the role of prior experience in adult learners' acquisition of postgraduate literacies in a postapartheid South African university
}

\author{
Linda Cooper \\ Higher and Adult Education Studies Development Unit, Centre for Higher Education \\ Development, University of Cape Town, Private Bag, Rondebosch, Cape Town 7700, South Africa \\ Email: Linda.Cooper@uct.ac.za
}

\begin{abstract}
Bio
Linda Cooper, PhD, is a senior lecturer in adult education at the University of Cape Town. Her research interests center around the role of experience in adult learning and the relationship between different forms of knowledge.
\end{abstract}

\begin{abstract}
The article takes as a case study a group of disability rights activists who were given access to a master's program via Recognition of Prior Learning. The question explored is "Can adult learners' prior experiential knowledge act as a resource for the successful acquisition of postgraduate academic literacy practices?" The analysis is framed theoretically by Bourdieu's notions of habitus, capital, and field. It is argued that adult learners' acquisition of postgraduate literacies is an outcome of the interplay between three factors: (a) student habitus and dispositions, (b) pedagogic agency, and (c) the nature of the disciplinary field. Although the program under investigation made complex demands on students, lecturers' understanding of student habitus enabled students' prior experiential knowledge to be tapped as a resource. However, students also exercised agency in negotiating the forms of academic habitus acquired, and the trajectory of their agency involved a mix of accommodation, resistance, and challenge.
\end{abstract}

\section{Keywords}

widening access, academic literacy practices, adult learners in higher education, social movements, recognition of prior learning, Bourdieu, transformation 


\section{Introduction}

Internationally, there has been a trend toward greater social inclusion, widening access to higher education, and lifelong learning (O'Donnel \& Tobbell, 2007). In postapartheid South Africa, increasing numbers of adult learners are seeking access to postgraduate, professional degree programs. Given the racially exclusive legacy of apartheid, however, many do not have the undergraduate degrees normally required to enter postgraduate study and are only able to gain access through Recognition of Prior Learning (RPL1). The question is then posed, Do the prior professional and life experiences of these adults act as a resource for their writing of research, or could such experiences act as a barrier to their acquisition of the literacies necessary to successfully complete a postgraduate degree?

This article is based on research conducted as part of a cross-disciplinary research project at a South African university, led by the institution's Postgraduate Writing Centre. The broader research project aimed to identify affordances for, and barriers to, postgraduate students' acquisition of academic literacies for the Writing Centre to develop sustainable practices to support students' writing of research. The project comprised a series of case studies across faculties and disciplines, among which was the Postgraduate Diploma/MPhil in Disability Studies (hereafter, the Disability Studies MPhil), the focus of this article.

The Disability Studies MPhil is of interest because it recruits a significant number of adult learners via RPL, in particular people who have been activists and policy advocates in the disability rights movement nationally and on the African continent. The main issue of interest is that of post-RPL access-in other words, learners' epistemological access to academic knowledge (Morrow, 2007) rather than the initial process of affording them institutional access. The key question posed and explored in this case study was this: In the context of higher education transformation in South Africa, can adult learners' prior experiential knowledge act as a resource for the acquisition of the academic literacy practices necessary for successful completion of postgraduate study?

The findings of this research indicate that this question cannot be answered in the abstract. Whether adult learners' prior experience acts as an affordance or constraint depends on three, interrelated factors: (a) the nature of the disciplinary subfield, (b) the nature of the program's curriculum and pedagogy, and (c) students' social and learning histories. The article will consider each of these in turn. First, it discusses the theoretical and methodological assumptions underpinning the research and describes the background to the case study.

\section{Conceptualizing learning, knowledge, and power}

This article uses the notion of academic literacy practices to capture what it is that students need to acquire if they are to achieve success at the postgraduate level. The concept is derived from the interdisciplinary field of new literacy studies, 2 which views literacy as a set of multiple, situated, social practices rather than as a cognitive attribute or decontextualized skill and emphasizes the ideologically contested nature of such 
practices. The academic literacies literature 3 focuses on access to academic discourse on the part of historically excluded students, foregrounds the politics of access to valued academic practices, and highlights student perspectives on academic writing.

The conceptualization of academic literacies as practices is linked to the framing of this research study through Bourdieu's theory of social practice. Practice is the relationship between habitus and field. Bourdieu's concept of habitus-a "durable, unconscious and embodied set of transposable dispositions" (Mutch, 2003, p. 384) formed out of past experiences and socialization processes (Bourdieu, 1990)—highlights the importance of attending to learners' social and learning histories. Similarly, the concept of capital, and the assumption that learners bring with them various forms of social, cultural, and symbolic capital (Grenfell \& James, 1998), recognizes learners as resource-ful rather than as having deficits in the form of learning needs. Capital and habitus do not function except in relation to a field, a set of objective relations between positions that structure "the distribution of species of power (capital) whose possession commands access to the specific profits that are at stake in the field" (Bourdieu \& Wacquant, 1992, p. 97). The use of Bourdieu's notion of field in this study acknowledges the specificity and power of the academy and of academic literacy practices as gate-keeping forces.

The question of change, and in particular the question of how students acquire new "patterns of learning habitus" (Herzberg, 2006, p. 1) that allow them to develop their postgraduate identity and voice, lay at the heart of this research project. The research sought to foreground the agentic potential of students, viewing them not as passive objects of pedagogy but as capable of negotiating their own way through academic literacy practices. The research was also interested in the direction or trajectory of that change. Would student strategies involve adaptation to dominant academic writing conventions or resistance? Would they be oriented "towards preservation of the distribution of capital or toward the subversion of this distribution"? (Bourdieu \& Wacquant, 1992, pp.108-109).

It was acknowledged that students' ability to develop the necessary academic literacy practices not only is a function of their own habitus, dispositions, and agency, but it may also be enabled or constrained by lecturers' pedagogic interventions. These in turn are influenced by lecturers' academic habitus, which is shaped their personal, social, and intellectual histories (Bloomer, Hodkinson, \& Billett, 2004). Conceptualizing pedagogy as agentic emphasizes the fact that within any academic discipline, the rules of the field are not cast in stone and there is always room for pedagogic creativity.

Bourdieu's theory does not directly address questions of curriculum and pedagogy, and it was to the literature on post access RPL that I turned for theoretical resources around these issues.

\section{Conceptualizing curriculum and pedagogy}

The analysis of the research data was influenced by the critical literature on RPL that draws on the classificatory vocabulary of Basil Bernstein to explore questions of 
curriculum, pedagogy, and epistemological access (see, e.g., Breier, 2006; Harris, 2006). A key principle of Bernstein is that of knowledge differentiation; that is, there are differences between academic knowledge and "everyday knowledge." In an earlier study of knowledge within the trade union movement, I demonstrated some of the distinctive features of those forms of knowledge generated through activist experience in social movements (Cooper, 2005, 2006). Acknowledging the distinction between different forms of knowledge makes it possible to pose the question of how everyday knowledge derived from activist, professional, and life experiences gets drawn onto and shapes students' acquisition of academic knowledge. At the same time, however, and conscious of critiques of Bernstein's categories being used to disparage everyday knowledge, the analysis here attempts to view different forms of knowledge not in hierarchical ways but as instances of the rich diversity of knowledge and to view the interaction between different forms of knowledge as potentially enriching society's knowledge base.

Harris (2006), focusing on postaccess RPL, argues that "the relationship between RPL and mainstream curricula is a complex one" (p. 56) and that the everyday or experiential knowledge of RPL students may receive different treatment by different curricula. Drawing on Bernstein's concepts, Harris (2004) introduces two different models of curriculum: a "soft-boundary" and a "hard-boundary" variety (pp. 27-28). In the soft-boundary curriculum, experiential knowledge is simply imported into the mainstream curriculum, whereas in the hard-boundary approach, the curriculum simply repositions the student on the other side of the boundary, leaving his or her experience behind. Harris (2006) poses the question as to whether RPL can act as a "two-way bridge between existing mainstream curricula and non-traditional students" (p. 71) moving dialectically back and forth between students' experiential knowledge and formal academic knowledge in an attempt to develop something new-and if so, under what conditions? This research draws on these concepts and metaphors to ask, How is the experiential knowledge of students (particularly those admitted through RPL) treated in the Disability Studies curriculum, and with what implications?

\section{Method}

The study adopted a critical, qualitative research methodology, with the research designed around one extended case study (Burawoy, 1998). Although case studies have limited empirical generalizability, they have significant potential for theory development and for extending the power of analytic generalization (Babbie \& Mouton, 2001). The choice of the case in this study was to some extent determined by questions of access: I had been drawn into the program's curriculum-planning group from an early stage to advise on RPL strategies, but I was confident that this was an exemplary case of a curriculum that attempts to be responsive to adult learners' prior experience.

Data collection relied on participant observation of classroom interactions and curriculum-planning meetings over a 4-year period. These, together with extensive documentation (including curriculum documents, student assignments and theses, and examiners' reports), informed my understanding of the hierarchies of capital within 
this field, the forms of pedagogy, and the relations between lecturers and students. In addition, I held ongoing conversations with lecturers and students over the 4-year period and conducted three in-depth, semistructured interviews with two members of the faculty and one student toward the end of the fieldwork. Interviews with the lecturers explored their perceptions of the cultural and symbolic capital brought by students and the pedagogic strategies they used to support students, whereas the student interview explored his professional and life experiences, what trajectories had led him into academic study, and the strategies he deployed to succeed on the course.

Although an ongoing process of interpretation ran parallel to the data collection, a more systematic analysis of the data was made toward the end of the fieldwork, drawing on Bourdieu's conceptual tools of habitus, field, and capital. Although I was careful not to force the data to fit predetermined categories, these three concepts helped cluster and reduce the data, surface key themes, and identify the relationships between the different elements of the case.

The methodological principles underpinning Bourdieu's work are to move beyond the dualism of subjectivism and objectivism, which has long plagued the social sciences (Bourdieu, 1991), and to capture the interplay between agency and structure as revealed through social practice. Theorization of the relationship between agency and structure has been significantly developed by Archer (2003), whose realist social theory has influenced the analysis in this study. The analysis first sought to establish how the "structural and cultural properties" (p. 3) of the institution and the discipline might enable or constrain student writing. As Archer argues, these remain unexercised unless activated by "the human project" (p. 6). The analysis went on to explore how these properties are mediated by (a) pedagogy, the agential powers of lecturers, and (b) student agencytheir power of reflexivity, to deliberate how to respond to the structural/cultural powers that have been activated, as expressed via their "internal conversations" (p. 9).

Although different data sets provided empirical indicators for Bourdieu's concepts, multiple data sources also served as a means of triangulating the evidence and adding to the validity of the conclusions. In particular, the interviews provided me with corroborative evidence for the conclusions that had begun to emerge out of my participant observations. To deepen the plausibility and credibility of my findings, I also sought critical feedback from the research respondents as to whether my interpretations were "recognizable" and "believable" (Durrheim, 1999, p. 46). Although my participant observer status afforded me easy access to data, I had to grapple with the tension between being both insider and outsider (Hammersley \& Atkinson, 1983), and I sought to be critically reflexive on my own positionality and the assumptions that might be influencing my interpretations.

\section{The disability MPhil: a program with transformatory intent}

The Disability Studies MPhil, launched in 2003, is a taught master's program, running over a 2 year period in blocks of 10 days each, so as to allow students from across southern Africa to participate. It comprises seven taught courses, including 
two on research methodology, in addition to which students have to complete a mini dissertation.

What makes this postgraduate program interesting as a case study is its transformatory intent, which is manifested in a variety of ways: It attempts to challenge boundaries both within the university and between academic and everyday knowledge as well as to critique the hegemonic view of disability in the field of rehabilitation sciences.

\section{Transforming curriculum: challenging the boundaries and rules of the field}

The subfield of critical Disability Studies has attempted to effect a paradigm shift within the wider field of rehabilitation sciences by challenging the biomedical model of disability (which views disability as a "disease" or "abnormality") that has historically been dominant in the field. The program locates itself firmly within critical social theory, linking disability to issues of race, gender, and class and drawing on feminist, postmodernist, and psychodynamic perspectives.

The program sought to establish itself as one of the university's few cross-faculty programs (ultimately without success 4 ), while also crossing traditional disciplinary boundaries and drawing in lecturers from four divisions in the School of Health and Rehabilitation Sciences (nursing, occupational therapy, physiotherapy, and communication sciences) as well as from psychology and sociology.

In addition to its interdisciplinary orientation, the program has sought to make more porous the boundaries between academic and everyday knowledge. From the outset, the program worked in partnership with disability rights organizations, which have constituted an active social movement in South Africa since the closing decade of apartheid, to negotiate the aims of the program and to develop the curriculum.

Movement leaders and activists have been drawn into the program not only as students but also as guest lecturers, with the program being viewed as a site for dialogue between academics and disability movement activists.

The program has asserted not only an academic identity but also an advocacy role for itself within the university, critiquing the institution for its lack of physical accessibility to disabled students as well as the neglect of disability as a curriculum issue in teaching programs. The Disability Studies MPhil has thus attempted to challenge the insulating nature of discipline-based curricula and has introduced a hybridized curriculum that engages in border crossings across disciplines as well as between the academy and everyday knowledge.

\section{Transforming pedagogy: a dialectic between theory and experience}

From the outset, the program put in place an RPL process aimed at providing access to those with significant organizational and life experience of disability but relatively low levels of formal education. A profile of students between 2004 and 2005 indicates 
that almost half of the 19 students were disabled and more than half were given access via RPL. The majority were women, and there was an even spread of students from rural and urban areas. Most were Black students whose native languages were other than English.

The experiential knowledge of disability activists is valued by lecturers because it is seen as providing insights uniquely available to those who are directly affected by disability and as something that can complement and enrich formal academic knowledge. As one lecturer put it, "I love working with them [adult learners with activist experience] because they are located out there. . . . There is a different suss about how society works in people who are out there." Another lecturer argued that those admitted via RPL are generally more socially critical than those who have entered the program with undergraduate degrees. Two external examiners' reports on a master's dissertation confirm that experiential knowledge is highly valued by academics in the subfield. This is reflected in statements such as the following: "Overall, this is a highly original piece of work, in terms of the subject matter and also the author's intimate insight/positioning within that context. This is a major strength" and "The candidate employs a convincing argumentative style as he clearly has first-hand knowledge of and valuable opinions on many of the issues raised."

The Disability Studies MPhil has adopted a soft-boundary approach to curriculum, in Harris' (2004) terms, but with a dialectical orientation, emphasizing not simply the importing of experiential knowledge but its potential to act as a resource to develop new knowledge. This is reflected in the statement of one lecturer, who said that experiential understanding of the field "is not enough"; students "need to substantiate experience with theory and critical analysis." It is reflected in teaching practices that attempt to move between the experiential knowledge of adult learners and formal, theoretical knowledge.

It is also reflected in approaches to assessment where oral examinations are given almost equal weight to written assessment. The valuing of oral presentations is closely linked to the program's aim of strengthening students' ability to act as disability rights advocates. However, it also signals recognition of the fact that orality (often combined with performance) is a mode of communication deeply embedded in the history and culture of Black South Africans and remains the dominant mode of communication in working-class communities and social movement contexts (Cooper, 2005). One lecturer explained her thinking behind oral presentations: "The idea is that some people are strong in written skills and others are strong in oral skills, and it's giving space for both." Oral forms of assessment afford greater possibilities for students from activist backgrounds to draw on their prior knowledge and enhance the dialectical movement of curriculum between theory and experience.

The Disability Studies MPhil's approach to curriculum and learning is part of its broader project of challenging the forms of symbolic capital represented by positivist, medical science, which have historically dominated this subfield, and of gaining recognition for new forms of symbolic capital based on the experiential knowledge of disability and on a critical, sociological perspective. A key factor making the enactment of 
such a curriculum possible is the ability of some of the lecturers, who themselves have been active in disability rights advocacy and policy development, to recognize and value the experiential knowledge of RPL students and to bridge the world of the academy and the world of disability activism.

Despite the transformatory intent of the program, however, it became apparent from early on that many students (particularly, but not exclusively, those admitted through $\mathrm{RPL}$ ) were struggling with the academic requirements of the program, particularly academic writing. The following sections outline the nature of the difficulties experienced by students and attempt to locate them within a broader context.

\section{Making sense of academic writing difficulties}

Despite the responsiveness of teaching staff toward students' experiential knowledge, the writing genres expected of students, particularly in the writing of their dissertation, are of a conventional academic kind, and it was in this terrain that many students encountered difficulties. The disjuncture between the competence of those students who worked in highly responsible, capable, and demanding jobs (e.g., in government or national policy forums or as leaders in activist organizations) and their English language and writing abilities was particularly apparent to one lecturer:

With a minority of exceptions (reflecting I think the formal academic backgrounds of the students) what was produced [in assignments] was cautious, often badly plagiarized, not clearly relevant, and not structured through the deployment of evidence towards a conclusion. This from people who each has showed the ability in class discussions, let alone their outside lives, to be courageous, learn from their own experience for themselves, articulate and share that, and act and work as powerful and effective advocates. . . . If I [had] marked on the basis of what I knew the students knew because of what they said in discussions and because of their life experience, then marks might have been higher.

The disjuncture between students' rich experiential knowledge and their academic writing ability was noted by another lecturer: "If you give people an oral, it's so rich! But then they are expected to write their thesis in Queen's English."

Many of the academic writing difficulties experienced were not restricted to those students who had come in via RPL. Graduates in occupational therapy, nursing, and physiotherapy struggled to make the transition from medical science writing to social science writing. However, those students coming from activist backgrounds seemed to face particular writing challenges. How should the difficulties encountered by these students be understood? It is argued that the research-writing difficulties experienced by those adult learners admitted via RPL derive not simply from their lack of prior academic training. Their difficulties need to be understood in the context of a number of further factors relating to (a) the interdisciplinary subfield, (b) the curriculum and pedagogy of this program, and (c) student habitus and the trajectory of students' agency. 


\section{The subfield: social movement knowledge on academic terrain}

It would seem on the surface that the Disability Studies MPhil, with its foregrounding of social critique and deconstruction and challenging of power relations, would have much in common with the kinds of everyday knowledge that circulate in social movements. However, there are a number of reasons why disability activists and advocates might not find it easy to meet the demands of academic writing.

One of these reasons was hinted at by a lecturer who taught a module on Diversity Studies. She argued that students who had gained access via RPL differed from graduate students on her course; although she did not view the disability activists as inferior intellectually, when a lecturer engages with them, "you have to work with concepts in a different way" as they come with "very definite agendas." To these students, knowledge is not neutral, and they have a strong tendency toward advocacy and the assumption of strong political positions. This point was echoed by another lecturer who supervised the first RPL student to successfully qualify with a master's degree. Although this student did not struggle to put forward her arguments, she struggled with how to write in a conventional academic style:

I think because of her activism. ... She shoots from the hip sometimes. And it was a struggle for her in terms of letting the data speak, and . . challenging her own frameworks. . . . That's where her struggle was. And then writing it academically because she speaks so passionately.

As suggested by my earlier research within trade unions, there are important differences between academic discourse and that which predominates in social movement contexts in South Africa. In these contexts, learning is powerful but often tacit; there is a distinctive use of narrative and oral-performative genres to mediate strong and explicit moral and political values; knowledge is both concrete and practical, and abstract and conceptual; and knowledge is not desired for its own sake but is a collective resource oriented toward articulating a vision of an ideal, future society (Cooper, 2005, 2006). These features construct a particular learning history and orientation to learning among participants. When those with this learning habitus seek access to the academy, they do not always find it easy to adapt to the conventions and demands of academic writing.

As with all knowledge, experiential knowledge does not always transfer easily across contexts (Lave, 1996). Harris argues that when experiential knowledge enters the academic terrain, it "becomes subject to the rules of the formal context," and its social basis, including power relations, are removed; "this reduces [its] efficacy as an active force against domination" (Harris, 2006, p. 65). In other words (as will be shown a little later), when students attempt to challenge academic conventions by drawing on their experiential knowledge, the knowledge-power relationships that they enjoy as activists within a vibrant social movement do not have the same efficacy within the academy. Students' experiential knowledge is therefore not necessarily able to travel-to function "translocally, across different physical and social spaces" (Blommaert, 2005, p. 69). 
In addition, the Disability Studies MPhil program does not necessarily make epistemological access easy. As noted earlier, the program attempts to weaken the boundaries between disciplines as well as between academic and everyday knowledge. Harris (2006) argues that generally speaking, in interdisciplinary programs, where the boundaries between disciplines are porous, the forms of knowledge and academic literacy practices that emerge are often more ambiguous than in singlediscipline-based programs. Teaching programs with weaker internal and external boundaries might make it easier for adult learners to draw on their experiential knowledge; at the same time, the program's hybridity and the tacit nature of the knowledge forms that predominate make it more difficult for the learner to recognize and acquire the appropriate academic literacy practices. If Harris is correct, then the very broad and multifaceted identity of the Disability Studies MPhil makes it difficult for students to recognize what it is that they are required to be and do (as competent students), even though many elements of the program may well speak to their activist experience.

I would argue that two further factors affect students' ability to meet the demands of postgraduate academic writing: (a) the complexity of the forms of capital valued by this program and (b) contestation around what constitutes cultural and symbolic capital in a field where historically separate subdisciplines, with different hierarchies of capital privileging different forms of habitus, have been brought together.

\section{Pedagogy and curriculum: complex and contested evaluative criteria}

The evaluative rules drawn on to assess students in the Disability Studies MPhil bear traces of the program's multiple aims and ambitions. As noted earlier, experiential knowledge is valued but is regarded as not enough: In their written projects, some students were criticized for being too anecdotal, lacking academic rigor, and not being able to write in a scholarly way. Despite the clear appreciation of students' experiential knowledge detailed earlier, external examiners' assessments of research dissertations were guided by a conventional set of academic criteria, including familiarity with the relevant literature and research methods, correct interpretation of the data, appropriate presentation of the dissertation, originality, and whether the work is worthy of publication in a recognized journal in the field. The limits of the field are pushed only so far, and to large extent, the Disability Studies MPhil still conserves the symbolic capital of the university as an academic institution.

In addition to traditional academic criteria, and in line with other postgraduate professional programs, the capacity for personal reflexivity is highly valued in the program, and conceptual tools need to be applied not only at the societal level but also at the interpersonal and intrapersonal (psychodynamic) levels. The kinds of personal reflexivity valued are very subtle: On the one hand, students are expected to demonstrate personal self-knowledge and self-critique, and in putting forward their arguments in the final part of their thesis, they are expected to find their own voice; on the other hand-as noted earlier - they also have to learn how to be less emotional in their arguments and to curb their passion for disability issues. 
In addition to the above, and reflecting the program's close relationship with the disability rights movement outside the academy, students are required to integrate theory and application and show a political and strategic feel for the game (Bourdieu \& Wacquant, 1992). For example, some of the questions posed to students in their oral exam included the following: What strategies would you use to mainstream disability studies within academic institutions? and The course has a partnership approach with DPSA5; how can we address the pressures on adult students who are working in fulltime jobs in the movement? Numerous other questions focused on organizational and institutional partnerships and alliances.

Thus, the dispositions and forms of capital that students are expected to acquire are varied, multiple, and complex. This is captured by a somewhat frustrated comment made by a staff member in a curriculum planning meeting: "What are we trying to produce? A professional or an academic researcher? An activist or a researcher?" Adding to the complexity of the evaluative criteria of this program is the fact that these criteria are contested. Within Bourdieu's framework, fields are always contested: "A field is simultaneously a space of conflict and competition . . . in which participants vie to establish monopoly over the species of capital effective in it" (Bourdieu \& Wacquant, 1992, p. 17). In the new, emerging, and still unstable field of disability studies, there is no consensus as yet around what counts as cultural capital and, thus, symbolic capital. In the curriculum-planning meetings, assumptions about what constitutes good research remained largely tacit, but when they did surface, there was disagreement and contestation over what the criteria should be, signaling different disciplinary histories. This contestation increases the ambiguity of the program's evaluative criteria and makes the task of students in decoding these criteria more complex.

This section has attempted to show how the academic writing difficulties experienced by adult learners admitted via RPL derive not simply from their lack of prior academic training. Their difficulties need to be understood in the context of the complexity of the forms of capital and dispositions valued in the field (including a critical analytic disposition, academic rigor, personal reflexivity, and a political and strategic sense) as well as contestation around what constitutes cultural and symbolic capital in the field.

Additionally, adult learners' difficulties in acquiring academic literacies should not simply be seen as a deficit. Students need to be seen as active agents, who at times choose to resist certain discourses. This argument will be illustrated with data from an in-depth interview with one of the first "movement activists" to enroll as a student on the course, but it is also supported by evidence from informal discussions with other students from similar backgrounds.

\section{Trajectory of Student Agency: Accommodation, Resistance, and Challenge}

Mandla (pseudonym) had been a national leader of one of the major disability rights organizations for 6 years when he began his MPhil in Disability Studies, and he had 
an even longer history of activism within the movement. According to him, leaders within the movement had begun to realize that the organization depended on experts to develop policy and interface with government, and they felt increasingly that they needed to indigenize this expertise "because we were not able to engage academics at an equal level." Thus, his initial motivation was extrinsic: "We needed it for the organization, not for me." Over time, Mandla became deeply engaged in the course and personally determined to succeed, despite having to juggle the stressful demands of study and work.

At the time of the interview, Mandla was just about to submit his thesis. His having reached this point is a clear indication that he had acquired new patterns of learning habitus, including the research skills and academic literacies necessary for successful postgraduate study. However, this process had not been without conflict and struggle. For example, he resisted what he called "the academic way of writing"; he related how some of his lecturers (perhaps those more accustomed to science writing) had insisted on the academic convention of not using the first person "l" in academic writing. He describes how he went to the university's Postgraduate Writing Centre to find out "what are the basic principles [of academic writing] ... what are the ... do's and don'ts." Asked how he felt about having to change his way of writing, he responded with a narrative of how a group of activists in his class challenged and resisted the imposition of academic discourse, but ultimately, they reached a "crossroads":

\footnotetext{
Well, this is part of the ... cross-roads we were subjected to, as we participated in the course. ... There [was] a high tension arising in the class because . . . we [felt] we understand issues, but [were] told: this is academic work, this is how you need to do it, this is how we need to behave, you know.
}

There were big arguments: "I remember $Y$ would become extremely emotional, and then people would say: Look, you either shape in or shape out [sic] . . . in terms of how we need to do these things." Asked to give an example of such an issue, Mandla referred to two competing approaches to disability: the medical and the sociological models. Students were told that

there was a need for us to recognize the role of medical knowledge, and that we can't just replace it and say it's of no use . . . there was this thing of saying: there are two sides of the coin ... you know. ... All the time you have to understand that as a student, you must also give [the other side]. [But as activists] . . you can't be in [the middle], you have to take a position [italics added] and say: this is what I feel.

Students from activist backgrounds found it difficult to accept that they could only "take a position" once they had dispassionately considered all the perspectives on an issue. This has some bearing on the point raised earlier regarding knowledge differentiation: Although pedagogy and knowledge in social movements are embedded 
in a strong but often tacitly held moral and political discourse, the academic literacy practices that Mandla was being inducted into required that all points of view be considered equally and dispassionately, and any positions adopted needed to be carefully and explicitly justified. In the end, students found themselves at a crossroads, where they had to choose either to "shape up or ship out," to accept the academic literacy conventions required or face the possibility of not succeeding on the course.

How might this adult learner's strategic adjustment and realignment of practice to the constraints of the academic field be viewed? Mandla's trajectory was a mixture of accommodation, resistance, and challenging of power relations. He had worked out the complex, specific logic of this subfield: that despite the challenges posed by a critical, sociological account of disability, the balance of power within the field meant that medical knowledge still held significant symbolic value. He had clearly acquired a feel for the game; however, this was a critical feel for the game, achieved through active engagement with the course lecturers and through creative practice. His exercise of agency required a degree of self-limitation and self-censorship; as Blommaert (2005) has noted, creative practice can only happen within certain contextual and structural constraints: "Creative practice . . . is something that has to be situated in the borderline zone of existing hegemonies. It develops within hegemonies while it attempts to alter them" (p. 106).

Despite this, Mandla did not ultimately accept the exclusive legitimacy of academic knowledge. In his interview, he expressed the conviction that there exists a wealth of knowledge within the disability rights movement that was only partially drawn on in the course and from which the university could gain: "And I think for me, this might be an opportunity for the university to learn something different, kind of see how they could integrate that knowledge and experience, you know, within what is being done." Thus, the process of self-limitation and self-censorship that he engaged in was a conscious one, and his learner habitus was critical in orientation. For Mandla, there was no misrecognition in Bourdieu's sense of the word: The power of the academy was not obscured.

This may not be a common response among mature learners entering postgraduate study. For example, Bamber and Tett (2000) refer to the "crisis of entitlement" experienced by many working-class adults entering higher education for the first time, whereas Anderson, Day, and McLauglin (2008), in a study of professionals studying on a taught master's program, found that students were "agentic with, rather than against the grain of the academy," accepting without resistance that their efforts should be framed within academic research and writing practices. In the South African context, however, many Black, working-class, adult learners who enter the academy bring with them a history of activism in social movements and traditions of social critique of dominant power relations. They are very aware of the history of racist, exclusionary practices in South African higher education, and this can generate a critical understanding of the power relations that continue to underwrite academic forms of knowledge and academic literacy practices. 


\section{Conclusions}

This article has explored the contextual conditions that influence adult learners' acquisition of postgraduate academic literacy practices. It has shown how adult students on an MPhil program with experience of activism in the disability rights movement bring with them considerable cultural capital: experientially grounded knowledge of what it means to be disabled, policy and contextual understanding, and experience of lobbying and advocacy. They are not "more" or "less" adept theoretically, but they experience the relationship between theory and practice in particular ways. Movement activists come with "very strong agendas": They emerge from an environment of advocacy that is ideologically directive, where actors take sides and are often passionately engaged and where theory must be useful and must inform practice. They find it difficult to reconcile themselves with the more dispassionate, pluralist approach required of them by research writing at the postgraduate level.

Adult learners from social activist backgrounds are likely to be attracted to postgraduate programs that draw on their experiential learning and that are oriented toward social critique and challenging of dominant power relations. What this case study suggests, however, is that such programs can be very demanding of students-perhaps even more so than more conservative programs that respect traditional disciplinary boundaries. This article has demonstrated the complexity of the postgraduate practices required of students in a field that is multidisciplinary, where the boundaries between academia and the everyday world of policy advocacy and social action are porous and where the evaluative rules (and hence the dispositions and forms of capital most valued) are multiple, complex, tacit, and contested.

The success or otherwise of adult learners in postgraduate study may be facilitated by lecturers' understanding of both sides of the boundary: their understanding of the habitus, dispositions, and forms of cultural capital that activist students bring with them as well as the forms of knowledge that the disciplinary field of study privileges. Nevertheless, the students' experiential knowledge does not easily or automatically translate into academic knowledge, nor does it retain its relative power when subjected to the academic rules of the game.

The research shows, however, that students exercise agency in negotiating the forms of academic habitus required of them. This agency is exercised in a space of interplay between creativity and determination, and its trajectory may involve a mix of strategies including accommodation, resistance, and challenge. Although ultimately, students' development of academic literacy practices involves a degree of selflimitation and self-censorship, there is room for creative practice. The feel for the game that Mandla acquired was a critical one, appreciative of the configurations of power within the field. It was also one that sought to engage with the already existing contestation in the field over which forms of symbolic capital should hold the most sway. Mandla's activist identity and habitus functioned not only as a constraint but also as an affordance: His history of social activism oriented him toward greater autonomy and creative practice as a postgraduate student. 
In concluding, the question might be posed, What is the broader political significance of social movement activists entering postgraduate study and acquiring an academic habitus? Might this result in the dilution of the power of activists' experiential knowledge and the longer-term co-optation of the disability movement? Or more positively from the perspective of the movement, might it result in moving mainstream educational institutions toward the demands of the movement and the incorporation of robust, social movement knowledge into the academy's knowledge archive? This question cannot be answered in this article, but the findings suggest that the latter possibility cannot be ruled out. The case study of the Disability Studies MPhil program illustrates the possibilities of a socially responsive academic program where student and pedagogic strategies both enable the acquisition of postgraduate literacy practices, while retaining an orientation toward the "subversion rather than the preservation" of the current distribution of capital in the field (Bourdieu \& Wacquant, 1992).

\section{Acknowledgments}

The author is grateful to the convenor of the MPhil in Disability Studies, members of the curriculum-planning team, and students on the program for their generosity in providing her with information for this study. The author is particularly indebted to members of the research team of the Post-Graduate Initiative at the University of Cape Town-Lucia Thesen, Moeain Arend, Clement Chihota, Shahieda Jaffer, Moragh Paxton, and Robert Prince-for their intellectual input and critical feedback. The author, however, takes responsibility for the arguments in this article.

\section{Notes}

1. Known as Prior Learning Assessment (PLA) in the United States and Accreditation of Prior Experiential Learning (APEL) in the United Kingdom.

2. See, for example, Baynham (1995).

3. For an overview, see Lillis and Scott (2007).

4. After 3 years of encountering institutional resistance to its straddling the Humanities and Health Sciences faculties, the MPhil program reluctantly relocated to the Health Sciences faculty only.

5. Disabled People of South Africa.

6. "Misrecognition relates to the ways (the) underlying processes and generating structures of fields are not consciously acknowledged in terms of the social differentiation they perpetuate." (Grenfell \& James, 1998, p. 25). 


\section{References}

Archer, M. (2003). Structure, agency and the internal conversation. Cambridge, England: Cambridge University Press.

Anderson, C., Day, K., \& McLauglin, P. (2008). Student perspectives on the dissertation process in a master's degree concerned with professional practice. Studies in Continuing Education, 30, 33-49.

Babbie, E., \& Mouton, J. (2001). The practice of social research. Cape Town, South Africa: Oxford University Press.

Bamber, J., \& Tett, L. (2000). The learning experiences of non-traditional students in higher education. Studies in Continuing Education, 22, 57-75.

Baynham, M. (1995). Literacy practices. Investigating literacy in social contexts. London, England: Longman.

Blommaert, J. (2005). Discourse. Cambridge, England: Cambridge University Press.

Bloomer, M., Hodkinson, P., \& Billett, S. (2004). The significance of ontogeny and habitus in constructing theories of learning. Studies in Continuing Education, 26, 19-43.

Bourdieu, P. (1990). The logic of practice. Stanford, CA: Stanford University Press.

Bourdieu, P. (1991). Language and symbolic power (J. B. Thompson, Ed.). Cambridge, MA: Harvard University Press.

Bourdieu. P., \& Wacquant, L. J. D. (1992). An invitation to reflexive sociology. Chicago, IL: Chicago University Press.

Breier, M. (2006). A disciplinary-specific approach to the recognition of prior informal experience in adult pedagogy: "rpl" as opposed to "RPL." In P. Andersson \& J. Harris (Eds.), Re-theorising the recognition of prior learning (pp. 77-96). Leicester, England: NIACE.

Burawoy, M. (1998). The extended case study method. Sociological Theory, 16, 4-33.

Cooper, L. (2005). Theorising pedagogy, learning and knowledge in the "everyday": A case study of a South African trade union (Unpublished doctoral dissertation). University of Cape Town, South Africa.

Cooper, L. (2006). Tools of mediation: An historical-cultural approach to RPL. In P. Andersson \& J. Harris (Eds.), Re-theorising the recognition of prior learning (pp. 221-240). Leicester, England: NIACE.

Durrheim, K. (1999). Research design. In M. Terre Blanche \& K. Durrheim (Eds.), Research in practice: Applied methods for the social sciences (pp. 33-59). Cape Town, South Africa: University of Cape Town Press.

Grenfell, M., \& James, D. (1998). Bourdieu and education: Acts of practical theory. London, England: Falmer Press.

Hammersley, M., \& Atkinson, P. (1983). Ethnography: Principles in practice. London, England: Tavistock.

Harris, J. (2006). Questions of knowledge and curriculum in the recognition of prior learning. In P. Andersson \& J. Harris (Eds.), Re-theorising the Recognition of Prior Learning (pp. 51-76). Leicester, England: NIACE.

Harris, J. A. (2004). The hidden curriculum of the recognition of prior learning: A case study (Unpublished doctoral dissertation), Open University.

Herzberg, H. (2006). Learning habitus and the dynamics of lifelong learning. Studies in the Education of Adults, 38, 37-47.

Lave, J. (1996). Teaching, as learning, in practice. Mind, Culture and Activity, 3, 149-164.

Lillis, T., \& Scott, M. (2007). Defining academic literacies research: Issues of epistemology, ideology and strategy. Journal of Applied Linguistics, 4, 5-32.

Morrow, W. (2007). Learning to teach in South Africa. Cape Town, South Africa: HSRC Press.

Mutch, A. (2003). Communities of practice and habitus: A critique. Organization Studies, 24, 383-401.

O'Donnel, V. L., \& Tobbell, J. (2007). The transition of adult students to higher education: Legitimate peripheral participation in a community of practice? Adult Education Quarterly, $57,312-328$. 